\title{
PHÝSIS KRÝPTESTHAI PHILEÎ. NATURALEZA Y METAFÍSICA EN LA CRISIS DE SER Y TIEMPO
}

\author{
PHÝSIS KRÝPTESTHAI PHILEÎ. \\ NATURE AND METAPHYSICS IN THE CRISIS OF BEING AND TIME
}

Jean-Paul Grasset B. ${ }^{1}$

Universidad de Chile

Recibido: 19.02.2019 - Aceptado: 15.03.2020

\section{RESUMEN}

\begin{abstract}
En este artículo, expondré el concepto heideggeriano de phýsis entre los años 1927-30. Este concepto aparece en la doctrina de la Welteingang des Seienden, en el marco de una 'radicalización de la ontología', proyecto metafísico que luego hará crisis y llevará a Heidegger a reinterpretar la pregunta por el sentido del ser como pregunta por la verdad del Ser. Mostraré que la cuestión de la phýsis aporta elementos en esa crisis y posterior cambio de enfoque, en el ámbito filosófico-histórico y en el fenomenológico. Mi hipótesis es que el empleo del concepto de phýsis en el contexto de la doctrina de la Welteingang des Seienden es un recurso especulativo que pretende aclarar el sentido en que el ente natural es, pero sin aparecer dentro del mundo, en términos de 'tránsito' desde el completo ocultamiento (phýsis) al desocultamiento (alétheia). Esto tendrá consecuencias respecto a la evaluación de la tradición metafísica, entendida como un preguntar por la phýsis en el doble sentido de ente en totalidad y ser de lo ente o esencialidad.
\end{abstract}

Palabras clave: Naturaleza; ocultamiento; phýsis; metafísica; ente.

\section{ABSTRACT}

In this paper, I will expound Heidegger's concept of phýsis in the years 1927-30. This concept appears in the doctrine of Welteingang des Seienden, in the frame of a 'radicalization of the ontology', a metaphysical project that later will generate a crisis, leading Heidegger to reinterpret the question of the meaning of being as the question of the truth of Being. I will show that the question of phýsis contributes with some elements to that crisis and to a later change of approach in the philosophical-historical field and the phenomenological one. My hypothesis is that the recourse to the concept of phýsis in the context of Welteingang des Seienden doctrine's is a speculative resource that aims to clarify the sense in which the natural being is, but without appearing within the world, in terms of a 'transition' from complete concealment (phýsis) to Unconcealment (alétheia). This will have consequences for the evaluation of the metaphysical tradition. The latter will be understood as a question about phýsis in the double meaning of being in totality, and the being of beings or essentiality.

Keywords: Nature; Concealment; Phýsis; Metaphysics; entity

1 Correo electrónico: jpgrasset@gmail.com. El presente artículo se enmarca en el Proyecto Fondecyt de Iniciación en Investigación 11190657, financiado por la Agencia Nacional de Investigación (ANID) del Gobierno de Chile, del cual el autor es responsable. Una primera versión parcial fue presentada en el IV Congreso Internacional de Fenomenología $y$ Hermenéutica, Universidad Nacional Andrés Bello, Santiago de Chile, 20 de noviembre de 2013. 


\section{INTRODUCCIÓN: ¿UN PROBLEMA DE LA NATURALEZA?}

Si hablamos de una cuestión de la naturaleza en el pensamiento de Heidegger, esta no parecería ser un problema fundamental del mismo. Aunque en un momento surgieron críticas acusando que la analítica existencial de Ser y Tiempo (en adelante, SuZ) abstraía de manera inadmisible lo natural y vital del ámbito de la existencia humana (Löwith 1984, 341ss.), parece claro, que en esa 'abstracción' operaba el interés de Heidegger por resaltar el fenómeno del mundo, lo que comportaba una determinada crítica a la orientación moderna hacia la naturaleza entendida en sentido físico-matemático. Por otra parte, en los años treinta y cuarenta, 'naturaleza' es para Heidegger objeto de estudio respecto a la noción presocrática de phýsis (que designa al ser como aparecer auto-configurante; $C f$. Heidegger 1983b 23), como también al momento de interpretar el mismo concepto en Aristóteles (Heidegger 1976239 ss.) En este enfoque, se trata de un sentido metafísico originario de phýsis, no reductible a 'naturaleza' en el significado físico-matemático ya consignado. Por lo tanto, si persistimos en hablar de un 'problema de la naturaleza', éste tendría carácter temático secundario dentro del proyecto filosófico de SuZ. En la ocupación de Heidegger desde los años treinta con la phýsis, su relevancia temática particular estaría supeditada al contexto más amplio del 'viraje' del pensamiento heideggeriano, i.e., inscrita en la movilización desde la pregunta por el sentido del ser hacia la pregunta por la verdad del Ser; desde la perspectiva trascendental-horizontal hacia aquella de la historia del Ser. En resumen, 'naturaleza' no indicaría una problemática de orden primario en la obra de Heidegger.

Sin embargo, ¿hay en ese pensamiento una problemática sobre 'la naturaleza'? Quizás el aparente carácter secundario radica en que 'naturaleza' no remite a un solo problema en el trabajo de Heidegger. Más bien, surgen diversos problemas mientras este autor desarrolla cuestiones como el ente natural (Heidegger 2002; 1975; 1976; 1978), el ente vivo y el organismo (1983a), la phýsis como principio de auto-ocultamiento (1976; 1978; 1983a; 1983b), el tema de la producción en los estudios sobre el arte (1950), el surgimiento desde sí en la naturaleza (1950; 1976, 1979), etc. En estas cuestiones, Heidegger intentaría conjugar estos distintos problemas recurriendo a elementos y terminologías similares; manteniendo en discusiones diversas, 
aunque vinculadas, nociones como 'naturaleza' o phýsis. Por lo tanto, 'naturaleza' sería un 'tema' en sentido débil, siempre remitido a discusiones más amplias que deben tratarse en tanto que enmarcadas en contextos específicos. No obstante, sin perjuicio de estas precauciones, podemos reconocer cierta conexión terminológica o de contexto general entre dichas cuestiones. Es posible rastrear elementos que articulen esas temáticas, en una fase determinada del pensamiento de Heidegger, o que puedan aparecer como líneas de continuidad en el paso de una fase a otra. Por lo tanto, me concentraré en la época específica 1927/30, con el objetivo de contribuir a la interpretación y discusión del lugar sistemático de 'naturaleza' y su problematización en el marco del establecimiento y posterior crisis del proyecto filosófico de SuZ. Sobre esa etapa, se han impuesto líneas interpretativas que la consideran como 'transición' de raigambre metafísica. Surgen planteamientos ambivalentes en ciertos análisis de Heidegger, que evidenciarían tensiones internas, que explicarían dicha crisis y transformación de su pensamiento en los años treinta. ${ }^{2}$ En este contexto, me interesa destacar algunas problemáticas específicasrespecto a la naturaleza y a la manifestación del ente natural, en conexión con la doctrina del 'ingreso del ente en el mundo', en la que Heidegger enfatiza la estructura de 'ocultamiento' a propósito de la noción presocrática de phýsis. Al respecto, ¿cuál es el rol que juega el recurso a esta noción en el marco de transición posterior a la publicación de SuZ?

En lo que sigue, situaré y expondré el recurso al concepto de phýsis. Este emerge en una problemática específica, inscrita en el contexto de un movimiento de 'radicalización de la ontología', que comporta un proyecto de corte metafísico que luego hará crisis. Al respecto, las bases textuales permiten sostener que el recurso al concepto de phýsis, a propósito de la problemática del modo de ser y manifestación del ente natural, guarda una relación determinada con la lectura de la phýsis que aparece, a fines de los años veinte, a la base de una peculiar interpretación de la metafísica. Igualmente, en dicho ámbito son visibles elementos que luego llevarán a Heidegger a terminar con el recurso positivo a la phýsis, cuando, a la luz de diversos frentes problemáticos, opere el mentado cambio de perspectiva entendido como reinterpretación de la pregunta por el sentido del ser hacia una pregunta por

2 Sobre este aspecto, vid. Biemel 1950; Courtine 1996; Crowell 2001; Figal 2008; Gadamer 1996; Greisch 2010; Haar 2002; Jaran 2006, 2008, 2010a, 2010b; Opilik 1993; Pöggeler 1993; Rubio 2004, 2008; Thurnher 1997; Van Buren 1994; Vigo 2008; Volpi 2012; Von Herrmann 1997; Xolocotzí 2004, 2009. Sobre naturaleza en Heidegger, vid., Gabriel 2017, Löwith 1984; Riedel 1989,1991; Rubio 2010. Respecto a naturaleza, phýsis y sus posibles conexiones con la vitalidad de lo vivo, vid. Beelman 1994; Dastur 1995; Ramos dos Reis 2010, 2012. 
la verdad del Ser. Por lo tanto, me parece que la cuestión de la phýsis aporta elementos clave, tanto en el ámbito filosófico-histórico con el ámbito fenomenológico. Mi hipótesis es que el empleo del concepto de phýsis en el marco de la doctrina de la Welteingang des Seienden implica un recurso especulativo que pretende aclarar el sentido en que el ente natural es, pero sin aparecer dentro del mundo, en términos de un tránsito desde el completo ocultamiento (phýsis) al desocultamiento (alétheia). Esta comprensión de la phýsis tendrá luego consecuencias respecto a la evaluación de la tradición metafísica, entendida como un preguntar por la phýsis en el doble sentido de ente en totalidad y ser de lo ente o esencialidad.

\section{EL PROYECTO FILOSÓFICO DE SUZ}

Para plantear correctamente el campo de análisis, es preciso comprender que 'ser y tiempo' no es sólo el título del magnum opus de Heidegger, sino también un proyecto y un problema filosófico. En otras palabras, se entiende que i), en sentido restringido, $S u Z$ nombra las secciones publicadas con ese título de un libro que queda 'inconcluso', es decir, que deja prometida una 'segunda parte' nunca publicada; ii) empero, en sentido amplio, SuZ es también la denominación de un proyecto filosófico, esbozado como tal en sus dos componentes centrales en el §8 de la obra; iii) ahora bien, SuZ nombra, además, un problema filosófico (la pregunta por el sentido del concepto de ser en general) y la perspectiva para abordarlo, que es lo que desarrolla la 'ontología fundamental'.

En virtud de la delimitación precedente, cabe indicar las características generales del proyecto filosófico establecido en SuZ. Como dije, la obra tiene como cuestión directriz la pregunta por el sentido del ser en general, cuyo horizonte de comprensión es el tiempo. En este contexto, Heidegger destaca el contraste fundamental entre el modo de ser de la presencia subsistente o estar-ahí delante (Vorhandenheit) y el modo de ser del existente humano que nosotros mismos somos: el Dasein. Bajo esta tesis hay una consideración histórico-filosófica: la tradición siempre ha intentado captar todo ente sólo a partir de la presencia subsistente y, con ello, ha entendido también el tiempo únicamente a partir del presente. En virtud de esta tesis, Heidegger investigará sobre el ser y el tiempo, apartándose de y polemizando con la mentada orientación metafísica tradicional. ${ }^{3}$ El punto de inicio para

3 Es precisamente a la luz de este postulado, como ha mostrado Jaran $(2008,391)$, que luego pudo ser motivo de sorpresa el giro metafísico de Heidegger en 1927/30, del que hay evidencias desde la lección de 1927 Die Grundprobleme der Phänomenologie. Además, en 1928 Heidegger muestra impulsos de realizar un "salto hacia la metafísica verdadera" (Heidegger 1978, 165). Este punto es precisamente -no hay que olvidarlo- uno de los más 
abordar correctamente el problema central será el despliegue de una analítica del Dasein, el existente humano, que es ente privilegiado en tanto que sólo él se cuestiona acerca del sentido del ser. El Dasein es caracterizado como apertura al mundo, i.e., a una dimensión de significatividad, en la que ya habita. Por lo tanto, la determinación del ser del Dasein implica reconocer el estar-en-el-mundo como su estructura fundamental. En consecuencia, el mundo es simultáneamente condición ontológico-universal y momento estructural del Dasein. Entonces, Heidegger conduce la pregunta por el ser hacia la analítica ontológica del Dasein, lo que implica metodológicamente que dicha analítica es punto inicial para investigar luego sobre cualquier otro modo de ser. De esta manera, en SuZ la pregunta por el sentido del ser interroga por el ser mismo en tanto que enraizado en la comprensibilidad del Dasein. Todo ente se manifiesta a partir de un horizonte de comprensibilidad, de un sentido, bajo ciertas determinaciones o condiciones. ${ }^{4}$ A esto se suma que toda experiencia entitativa está enraizada en una comprensión previa del ser. En ella la dimensión de ser se abre como sentido, y el Dasein lo comprende. El proceso en que el ser se configura como sentido es el tiempo.

Por lo tanto, el desarrollo del programa de $S u Z$ implica dos tareas: i) una 'analítica del Dasein', que estudia las estructuras ontológicas del existente humano -el agente situado en el mundo- en cuanto que ente abierto comprensivamente al ser; ii) la "destrucción de la historia de la ontología", que comporta la revisión crítica de la tradición ontológica. Estas tareas corresponden a la división de la obra programada en dos partes: la primera, llamada "La interpretación del Dasein por la temporeidad y la explicación del tiempo como horizonte trascendental de la pregunta por el ser"; la segunda, titulada "Rasgos fundamentales de una destrucción fenomenológica de la historia de la ontología al hilo de la problemática de la temporeidad" (Heidegger 2006a, 39). Esta división programática sigue lo abordado sobre la "doble tarea del planteamiento de la pregunta por el ser", atendiendo especialmente a las directrices fijadas para ello en el $\S 5$ de la misma obra. Según este plan, la analítica del Dasein culminaría con un estudio sobre "Tiempo y ser", sobre el ser en cuanto tal. Tal debía ser la Tercera y última

relevantes a la hora de ponderar un desarrollo y crisis de un proyecto filosófico que se basa en la determinación y desarrollo de un problema filosófico desde una determinada perspectiva de análisis.

4 "Y cuando preguntamos por el sentido del ser, la investigación no se torna por eso profunda, ni intenta alcanzar, a costa de cavilaciones, algo que estuviera detrás del ser, sino que pregunta por el ser mismo en tanto que inmerso en la comprensibilidad del Dasein. El sentido del ser no puede ser jamás contrapuesto al ente o al ser en cuanto 'fundamento' sustentador del ente, puesto que el 'fundamento' sólo es accesible como sentido, aunque sólo fuere como el abismo del sinsentido." (Heidegger 2006a, 152) 
sección de la primera parte, que antecedía la discusión con la historia de la ontología — tercera sección y segunda parte que, como sabemos, nunca fueron publicadas como tales. ${ }^{5}$

\section{RADICALIZACIÓN DE LA ONTOLOGÍA}

Luego de SuZ, Heidegger continúa el programa ontológico-fundamental. La lección Los problemas fundamentales de la fenomenología abordará, como 'nueva elaboración' de la tercera sección de $S u Z^{6}$, los problemas pendientes de esa obra, a nivel de estudios sobre el tiempo y de comprensión del ser. En el inicio de la lección, Heidegger considera cuáles deben ser los 'problemas fundamentales' de la filosofía. Sin embargo, no entra directamente en ellos, sino que realiza un rodeo consistente en "la explicación de determinados problemas particulares" (Heidegger 1975, 1). Estos son: la 'diferencia ontológica', la 'articulación fundamental del ser', las 'modificaciones del ser y la unidad de su multiplicidad' y el 'carácter de verdad del ser' (Heidegger 1975, 24-25; 169-174; 250-320). ${ }^{7}$ Mediante ellos habrá de hacerse manifiesto hasta qué punto es necesaria la filosofía como ciencia, pues para Heidegger exponer tales problemas implica fundamentar la afirmación de que la filosofía es "ciencia del ser". Esto equivale a sostener que la filosofía es ontología. ${ }^{8}$

${ }^{5}$ Hay que recordar que la 'Primera Parte' efectivamente publicada de $S u Z$ se reduce a la Primera sección, donde encontramos una interpretación del Dasein en sus estructuras fundamentales, que quedan resumidas en la idea de 'cuidado'. A esto se agrega la Segunda sección, donde Heidegger establece que el sentido de ser del Dasein, es decir, del cuidado, es la temporeidad. 54).

6 Sobre los pormenores de este asunto, véase el estudio de Von Herrmann (1997, 47-

7 El desarrollo completo de estos problemas no es realizado en esa lección de 1927. Sólo la 'diferencia ontológica' es tematizada con la profundidad prometida por el programa de la lección. Respecto al carácter incompleto de estos problemas fundamentales y cómo afectan el conjunto de la lección, véase Von Herrmann 1997, 57-63. Por otra parte, cabe hacer notar que en el curso sobre Leibniz de 1928, Heidegger repite abreviadamente el planteamiento y contexto sistemático de la cuestión del ser y sus cuatro problemas fundamentales. Según lo sostenido allí por el autor, la expresión universal ser "incluye los cuatro problemas señalados: diferencia ontológica, articulación fundamental del ser, carácter veritativo del ser y regionalidad del ser y unidad de la idea de ser" (Heidegger 1978, 193).

${ }^{8}$ Como ha remarcado Jaran $(2010 \mathrm{~b}, 208)$ la primera indicación positiva de Heidegger hacia la metafísica aparece en el curso de 1926/27 Historia de la filosofía desde Tomás de Aquino a Kant (Heidegger 2006b, 7-10). Allí Heidegger plantea la oposición entre el "concepto vulgar" (o "popular": vülgarer) de metafísica y la "metafísica científica". La primera no se aproxima al ser a partir de su origen óntico", sino que se mueve en la "sobriedad y frialdad del concepto" (2006b, 7). Este asunto se conecta con la lección Los problemas fundamentales de la fenomenología y la 'ciencia del ser' hace poco señalada. En efecto, como correctamente indica Jaran, Heidegger sostiene en 1927 que "la ciencia trascendental del ser no tiene nada que ver con la metafísica popular (...) más bien, el 
Como se puede apreciar, con esto Heidegger pretende dar una respuesta metafísica a la cuestión del ser. En el periodo 1927/30, Heidegger intentará transitar un camino metafísico: aquel cuyo 'renacimiento' rechazaba con desconfianza en el tratado de 1927 y que luego, en los años treinta, se le impone como algo que superar. Por lo tanto, este "periodo metafísico" de Heidegger debe ponderarse como un punto de inflexión en el curso de su pensamiento y obra.

Ahora bien, en Los problemas fundamentales de la fenomenología, Heidegger plantea que el problema fundamental de la metafísica exige, al radicalizarse y universalizarse, una interpretación del Dasein que atienda a la temporeidad, para iluminar la posibilidad intrínseca de comprensión del ser $\mathrm{y}$, con ella, la de la ontología. Respecto a esta última, reafirma que es entendida solo en el desarrollo de la problemática fundamental, expuesta en las cuatro dificultades mencionados. Acto seguido, recuerda los componentes de esta operación filosófica en torno a la idea de ontología fundamental: un compuesto total de fundamentación y desarrollo de la ontología. Ella es primero analítica del Dasein y luego analítica de la temporaneidad del ser. Tal como se expuso, la analítica temporánea "es a la vez el giro o inflexión en que la ontología retrocede expresamente hacia la óntica metafísica en la que de modo implícito siempre ha permanecido" (Heidegger 1975, 201). El mencionado movimiento de radicalización y universalización operado en la ontología la llevará a esa inflexión, marcha atrás o conversión en metontología, que está latente en ella misma. Ahora bien, ¿cuál es la base de esta operación filosófica que Heidegger proyecta? La radicalización descrita está basada en una cierta interpretación de la 'metafísica', que se apropia interpretativamente ciertos aspectos de la tradición filosófica. ${ }^{9}$ En la lección sobre Leibniz de 1928, por ejemplo, Heidegger explicita que ontología fundamental y metontología constituyen en su unidad el concepto de metafísica:

concepto científico de metafísica es idéntico al concepto de filosofía en general -ciencia crítica trascendental del ser, ontología" (Heidegger 1975, 23; Cf. Jaran 2010b, 208).

9 Es importante destacar la conexión del giro metafísico con la recepción antropológica que tuvo SuZ luego de su publicación. Como nota Jaran $(2008,391-392)$ tales 'malentendidos' llevan a Heidegger a recalcar la intención ontológica -y no antropológicade SuZ: no busca responder la pregunta por el hombre sino la pregunta por el ser.Heidegger pretende destacar que el tratado de 1927 intenta dar cuenta de una relación no antropocéntrica entre hombre y ser. Por lo tanto, la 'radicalización de la ontología' debe entenderse en el contexto de aquella "metafísica del Dasein" que Heidegger pretende elaborar en 1927/30, manteniendo las tesis fundamentales de $S u Z$ pero radicalizando su temática para mostrar su interés ontológico. Como ejemplo de recepción 'antropologizante' de SuZ, vid. Misch 1967. Heidegger responde a esta lectura en la lección sobre idealismo alemán de 1929, mostrando cómo la metafísica del Dasein se opondría a la antropología filosófica (Heidegger 1997, 131-139, 244, 310). Para un estudio global de la 'metafísica del Dasein', vid. Jaran 2010a. Sobre la concepción heideggeriana del 'hombre' en disputa con la antropología filosófica, vid. Muñoz 2008. 
En esto no se expresa más que la variación de un problema fundamental de la filosofía misma y que ya antes (...) fue tratado con el doble concepto de filosofía como próte philosophía y theologia. Y esto es sólo la concreción respectiva de la diferencia ontológica, esto es, la concreción de la realización de la comprensión del ser. Con otras palabras: la filosofía es la concreción central y total de la esencia metafísica de la existencia. (Heidegger 1978, 202)

Este enfoque de Heidegger hace corresponder filosofía primera y teología -tomadas de Aristóteles- con la ontología fundamental y la metontología (pregunta por el ente en totalidad), respectivamente. En la Introducción de esta lección, Heidegger desarrolla una elaboración preliminar del concepto de filosofía. Se detiene en el concepto aristotélico de filosofía, según el cual 'hay una cierta ciencia que investiga el ente en cuanto ente y aquello que le pertenece como tal', que luego llamará 'filosofía primera'10, a la que corresponderá investigar el ente en tanto que es ente, y esclarecer lo que es y le corresponde como tal. A ojos de Heidegger, esto funda la filosofía como ciencia del ser: ciencia del ente en cuanto ente significa ciencia del ente desde la perspectiva de aquello que hace al ente el ente que es: el ser. Sin embargo, Heidegger no se detiene en esta caracterización, sino que recurre al momento en que Aristóteles habla también de la filosofía auténtica como "teología".11 Al tomar la doble caracterización aristotélica de la filosofía como ontología y teología, Heidegger expone la necesidad de mostrar en qué sentido la 'teología' pertenece a la esencia de la filosofía. A partir de esta dualidad Heidegger busca, mediante la tensión entre filosofía y teología, un camino de "radicalización" del concepto de ontología $(1978,17)$. De hecho, Heidegger plantea que en la cuestión ontológica fundamental de la filosofía se trata de algún modo simultáneamente con la totalidad de lo ente y, por ello, también con la existencia humana; eso estaría presente en la mentada dualidad aristotélica. Esta es interpretada por Heidegger como tensión entre i) ontología fundamental y ii) la cuestión del ente en totalidad y la pregunta por el mundo. En este sentido, Heidegger se refiere a este tránsito desde la ontología fundamental hacia la ontología general hablando de "metafísica

10 El pasaje de Aristóteles que Heidegger comenta es Metafísica VI, 1, 1003a 21 ss, analizado en Heidegger 1978, 12 ss. Por otra parte, respecto al asunto de la 'filosofía primera', Cf. Heidegger 1997, 30.

11 Esta operación heideggeriana con la dualidad aristotélica mencionada ha sido puesta de relieve por Rubio (2008, 293 ss), quien subraya que Heidegger entiende esta teología como referencia a "los fundamentos de lo supra-potente (Übermachtiges) que se manifiesta en los entes patentes" (Heidegger 1978, 13). Heidegger interpreta el tó théion aristotélico como "el ente sin más -el cielo: lo omniabarcante y lo dominante, aquello bajo y en lo cual estamos arrojados, aquello que nos sorprende (...) lo supra-potente. El theologeín es un considerar el kósmos" (Heidegger 1978, 13). Sobre la 'constitución ontoteológica' de la metafísica del Dasein, vid. Jaran 2010b, 212-215; véase también a este respecto Tengelyi 2014, 33ss, que recuerda la inspiración heideggeriana en Aristóteles, a fines de los años veinte, para afirmar que la tarea de la filosofía es de índole metafísica. 
del Dasein" y, siguiendo esta orientación, sostiene que "la ontología fundamental no agota el concepto de metafísica" (Heidegger 1978, 199). ${ }^{12}$ En otras palabras, hay aquí una distinción entre la pregunta ontológica por los modos de ser (i.e., por las formas más generales en que los entes son desvelados: Zuhanden, Vorhanden, Dasein, Natur, etc.), y la pregunta metafísica por el ente en su totalidad como precondición para todo desvelamiento.

Ahora bien, en el curso de 1928/29 Introducción a la filosofía, Heidegger radicaliza esta dualidad como tensión y co-pertenencia entre la pregunta por el ser y el problema del mundo (Heidegger 1996, 391). Entiende que la cuestión del ente en total, sin perder su relevancia, debe ser integrada (junto a problemáticas como el fundamento, la nada, la libertad, la trascendencia) en lo que denomina "problema del mundo" $(1996,393)$. Esta problemática da, entonces, la perspectiva unitaria y global para desplegar y abordar las cuestiones de la ontología. Heidegger explica que, así como el problema del ser originariamente planteado se convierte en el problema del mundo, este último, al ser desarrollado, revierte en el problema del ser. Luego, concluye que "ambos problemas constituyen la problemática en sí unitaria de la filosofía". El compuesto de esta unidad "no es sino la problemática de la trascendencia" (Heidegger 1996, 393). ${ }^{13}$ Esta operación ocurre en consonancia con el enfoque interpretativo de carácter metafísico asumido por Heidegger. Sin embargo, dicho enfoque sufrirá variaciones en su contenido en la lección 1929/30 Los conceptos fundamentales de la metafísica, debido a una tensión que implica la correspondencia sostenida entre 'ontología' y 'metafísica'.

Ya establecido en rasgos generales el despliegue del proyecto filosófico de $S u Z$ en las lecciones posteriores a la publicación de ese tratado, ¿cómo aparece y qué rol juega en ese marco la cuestión de la naturaleza y, luego, el concepto de phýsis?

12 Este planteo es reafirmado en la lección de 1929: "Fundamentación de la metafísica, y luego, metafísica del Dasein” (Heidegger 1997, 41).

13 En el ámbito en que nos encontramos, se observa un potenciamiento del concepto y problema de "mundo". Aunque "mundo" no deja de entenderse como horizonte de manifestación para toda venida a presencia entitativa (Vigo 2008, 162-163n), sin embargo, el estar-en-el-mundo ofrece ahora un punto de vista amplio, un horizonte unitario para tratar el conjunto de los problemas ontológicos, como se aprecia en la lección de 1928/29. Allí se afirma que "el mundo es el todo de la constitución de ser, no solo de la naturaleza, el estar unos con otros histórico y el ser sí mismo del Dasein, sino que el mundo es la específica totalidad de la multiplicidad de ser (Seinsmannigfaltigkeit), que en el coestar con otros, en el estar en medio de los entes y en el ser sí-mismo unitariamente se entiende y comprendemos" (Heidegger 1996, 309). Para obtener dicha totalidad, lo que se debe hacer, según Heidegger, es "determinar la específica totalidad de ese ser todo, ya comprendida en el Dasein, la organización interna de su totalidad de ser" (Heidegger 1996, 309; Cf. pp 393394). 


\section{NATURALEZA, MUNDO Y OCULTAMIENTO}

\section{a) Naturaleza y mundaneidad en $\mathrm{SuZ}$}

Para responder pregunta planteada en la sección anterior, es preciso ver el surgimiento de la problemática mencionada a partir de lo establecido en SuZ sobre la cuestión de la naturaleza. Como advierte Rubio (2010, $328^{14}$ ), los análisis heideggerianos al respecto buscan i) indagar sobre un campo determinado de entes y su posibilidad de manifestación; y ii) deslindar la ontología del Dasein frente a las ontologías tradicionales, centradas en el ente que está-ahí delante. En definitiva, en este momento Heidegger se aproxima críticamente a una noción de naturaleza como sustrato permanente, noción que, a sus ojos, proviene de la teoría metafísica de la sustancia. Esto ejemplifica, para Heidegger, cómo la tradición intentó, sin acertar en el fenómeno, aprehender el 'mundo', entendiendo el ente que está-ahí dentro del mundo como una enumeración de "cosas" intramundanas, fundada en la esencia de las cosas naturales ( $C f$. Heidegger 2006a,63). Ante esto, el autor sostiene que la tradición encubrió el estar-en-el-mundo como constitución del Dasein, omitiendo parejamente el fenómeno de la mundaneidad. Considerado histórico-filosóficamente, esto habría implicado una interpretación del mundo a partir de una noción sesgada de naturaleza, centrada en el ente subsistente intramundano que no está en absoluto descubierto. De esa visión tradicional se concluye que el existente humano sólo descubre la naturaleza en un modo determinado de su estar-en-el-mundo: como cierta "desmundanización del mundo" (Cf. Heidegger 2006, 93; cf. Rubio 2010, 330). Según Heidegger, "La 'naturaleza', como concepto categorial global de las estructuras de ser de un determinado ente que comparece dentro del mundo, jamás puede hacer comprensible la mundaneidad" (Heidegger 2006a, 65). Por el contrario, los modos de ser del ente intramundano (estar a la mano y estarahí delante) sólo aparecen como tales en el mundo que el Dasein (como estaren-el-mundo) abre significativamente. La intramundaneidad, por lo tanto, implica relatividad constitutiva respecto al Dasein.

Ahora bien, en contraposición a esa comprensión tradicional de la naturaleza recién descrita, Heidegger entiende la naturaleza como un modo de ser, es decir, como una de las formas generales en que el ente es desvelado; un horizonte de experiencia. En ella distinguirá entre la naturaleza del

14 Sigo aquí la lectura interpretativa de Rubio 2010 sobre el vínculo entre naturaleza y mundo en el contexto de $S u Z$ y la doctrina de la Welteingang. Ahora bien, la evocación de esos destacados planteos también tiene el interés de evaluarlos críticamente, sobre todo a propósito de lo que en ellos se entiende como una suerte de 'autonomía relativa' en el modo de ser del ente natural. Esa misma revisión me permitirá avanzar interpretativamente hacia la cuestión del recurso a la phýsis -solamente señalado por Rubio- en la lección de 1929/30 y sus consecuencias respecto al devenir metafísico del proyecto de $S u Z$ en aquel periodo. 
mundo circundante (Umweltnatur, referida al horizonte de experiencia instrumental y operativa de los entes naturales) y el mundo natural (Naturwelt, horizonte de la naturaleza en sentido físico-matemático). En este contexto, ¿cómo se explicita el estar-ahí delante natural? Heidegger señala:

No todo estar-ahí delante es un estar-ahí de cosas. La 'naturaleza' que nos 'rodea' es indudablemente un ente intramundano, pero no tiene el modo de ser de lo a la mano ni de lo que está-ahí delante al modo de una 'cosa natural'. Como quiera que se interprete este ser de la 'naturaleza', todos los modos de ser del ente intramundano están ontológicamente fundados en la mundaneidad del mundo y, por ende, en el fenómeno del estar-en-el-mundo. (Heidegger 2006a, 211)

Según el pasaje, todos los modos de ser del ente intramundano se fundan en la mundaneidad. Al respecto, Rubio $(2010,331)$ indica que esto comporta una radicalización del vínculo entre naturaleza y mundo, pues no solo la manifestación del ente natural se orienta hacia la estructura del mundo, sino también el modo de ser de ese ente natural. Esto implica, sostiene, que la naturaleza depende de la mundaneidad aun cuando no se aclare el estarahí natural. Empero, ¿se trata de una radicalización? Al menos en principio, el planteo citado implica que los modos de ser suponen unas condiciones de inteligibilidad para el descubrimiento del ente. Por lo tanto, si los modos de ser (i.e., formas en que los entes son desvelados) dependen de la manifestación, no es sorpresivo que estén fundados en el fenómeno del estar-en-elmundo. Esto es así aun cuando Heidegger no termine de aclarar el estar-ahí natural. Por cierto, la correcta ponderación del fondo de este asunto implica indagar sobre cómo Heidegger aclara dicho elemento y cómo eso puede afectar su tesis recién revisada.

\section{b) El marco de la metontología: ente natural y doctrina del in- greso del ente en el mundo}

Luego de SuZ, Heidegger desarrolla una noción de 'naturaleza' algo distinta a la presentada en esa obra, de la que cabe analizar el modo de ligazón con el ente intramundano. Ahora Heidegger hablará de naturaleza 'en sentido originario' (Heidegger 1976, 155). En ese contexto, el ente natural es un modo especial del estar-ahí-delante. En la lección de 1927 Los problemas fundamentales de la fenomenología, afirma que el modo peculiar de estar-ahí del ente natural implica que este es independiente del Dasein. Ente intramundano es, por ejemplo, la naturaleza, pero la intramundaneidad no pertenece a su ser:

En el trato con este ente, con la naturaleza en más amplio sentido, comprendemos que este ente es, en tanto que está-ahí delante (...). Es incluso aunque no lo descubramos, aunque no lo encontremos dentro de nuestro mundo. A este ente, a la naturaleza, le corresponde la intramundaneidad sólo cuando es descubierto como 
ente. A la naturaleza no le puede corresponder la intramundaneidad como una determinación, ya que no se ha aportado ninguna razón que haga evidente que necesariamente tenga que existir un Dasein" (Heidegger 1975, 240).

¿Cómo afecta ese planteamiento lo dicho previamente en SuZ? Allí se decía que todos los modos de ser del ente intramundano se fundan en la mundaneidad y, por ende, en el fenómeno del estar-en-el-mundo. Ahora se dice que la naturaleza puede ser también aunque no la descubramos ni encontremos "dentro" de nuestro mundo, e incluso aunque no exista ningún Dasein (Heidegger 1975, 241). Es preciso notar que el pasaje indica que al ente natural sólo le corresponde la intramundaneidad una vez descubierto como ente, pero que no le corresponde como determinación. ¿Cómo un ente intramundano 'es' sin ser descubierto? ¿Hay aquí contradicción o relativización? ¿0, por el contrario, es un planteamiento coherente con el programa de $S u Z$ que prosigue o radicaliza una línea al respecto?

El lugar para indagar sobre este asunto es la doctrina heideggeriana del ingreso del ente en el mundo (Welteingang des Seienden). Ella se ubica en el contexto del despliegue de la metontología en trabajos posteriores a SuZ, donde subyace, como ya indiqué, una "radicalización de la ontología". Se produce entonces una inflexión del programa de SuZ: el tránsito al plano ontológico general -una vez realizada la ontología fundamental- vendría dado por el desarrollo de la cuestión del "ente en totalidad". Este movimiento amplía el desarrollo de la ontología fundamental hacia la "metontología", estableciendo luego una tensión entre pregunta por el ser y pregunta por el ente en totalidad ( $C f$. Heidegger 1978, 199).

La doctrina de ingreso del ente en el mundo plantea que el Dasein, el existente humano, es un trascender; un movimiento de trascendencia o sobrepasamiento del ente en dirección a su ser y, en último término, al mundo, y luego un regreso descubridor hacia el ente (Cf. Heidegger 1975, 423; 1978, 204). El Dasein se da su mundo proyectando sus posibilidades, y en esa proyección se constituyen estructuras referenciales en que el ente puede mostrarse a nosotros, comprendido en la unidad referencial de significatividad ( $C f$. Heidegger 1976, 158). De acuerdo con esto, "solamente el Dasein como existente da la oportunidad de ingreso al mundo" (Heidegger 1978, 251). El autor precisa que lo que está-ahí-delante "es el ente tal como él es incluso aunque no se haga intramundano, aunque no le acontezca el ingreso en el mundo o no se le dé ninguna ocasión para ello" $(1978,251)$. La intramundaneidad no pertenece a la esencia de lo que está-ahí delante, sino que es condición de posibilidad de que lo que está-ahí delante en cuanto subsistente pueda darse a conocer en su en-sí; i.e., que el Dasein lo experimente y comprenda en su en-sí o, para decirlo de una manera calculadamente equívoca, 
en su 'ser tal como es'. El ingreso en el mundo es condición para que lo subsistente, el ente que está-ahí-delante, se manifieste en su carencia de necesidad de entrar en el mundo (i.e., como el ente que es, o mejor, que hay). Con esto, como he venido indicando, Heidegger afirma la dependencia manifestativa del ente natural respecto del Dasein, pero, a la vez, sostiene la independencia en cuanto ente, esto es, independencia del en-sí del ente en tanto factum brutum de que es, de que hay ente y para esto no es necesario que haya Dasein, aunque eso sea algo que solo sabemos cuando descubrimos el ente.

Estos argumentos de Heidegger implican una recuperación de las raíces ónticas de la ontología mediante la pregunta metafísica por el ente en su totalidad como precondición para todo desvelamiento. En ese marco, sólo por el mencionado hecho bruto de que hay ente puede haber descubrimiento del ente y comprensión del ser. La metontología es precisamente el modo en que Heidegger incluye esa dimensión en sus consideraciones. En efecto, como indica M. Gabriel, "sin Dasein en todo caso se habrían dado objetos inefables, pero no se habría dado ningún mundo" $(2017,279)$. En otras palabras, o bien no hay nada, o bien por lo menos no tenemos ningún acceso a un ser en sí de lo que es, entendido de esa manera, si no construimos además siempre un trasfondo frente al que puede aparecer el ente en general (Heidegger 2013-2014; citado en Gabriel 2017, 280).

Ahora bien, a propósito de esto recordemos otra vez lo dicho sobre naturaleza, ente natural y mundaneidad. En SuZ se sostenía que, cualquiera fuese el modo en que se interpretase el ser de la 'naturaleza' (con comillas), todos los modos de ser del ente intramundano se fundan ontológicamente en la mundaneidad del mundo, y por ello en el estar-en-el-mundo. Posteriormente sostuvo (Heidegger 1975, 240) que en el trato con ese ente, con la naturaleza en más amplio sentido (y sin comillas), ese ente (el ente natural) es, en tanto que está-ahí-delante, incluso aunque no lo descubramos ni lo encontremos dentro de nuestro mundo. Sólo le pertenecería la intramundaneidad en tanto descubierto, pero no en su en-sí como determinación, porque no hay razón que evidencie la necesidad de que tenga que existir Dasein. Sin embargo, como acabamos de decir, sin Dasein sólo habría objetos inefables, o más bien no habría nada. Como han notado algunos especialistas ( $C f$. Rubio 2010, 332; Gabriel 2017, 280), hay una dificultad en el léxico de Heidegger toda vez que habla de naturaleza con comillas, lo que puede entenderse como sugerencia de que habría otro concepto de naturaleza, que no se entendería como modo de ser. La naturaleza, en el sentido de 'lo que nos envuelve' (aunque no es el único sentido), es un ente intramundano, dice Heidegger (2006a), y, con ello, en SuZ queda abierta la dilucidación de cuán- 
tos modos del ente intramundano han de establecerse. Posteriormente, habla de naturaleza sin comillas y en sentido amplio, y la llama, al mismo tiempo, "este ente", es decir, el ente natural. Claramente, en estos planteos hay una ambivalencia. ${ }^{15} \mathrm{Al}$ respecto, me parece acertada la lectura de Gabriel, según la cual habría en ellos un esfuerzo de Heidegger por evitar ser acusado de antirrealismo óntico, esto es, de sostener que no se habría dado ningún objeto o cosa real si nadie los hubiese individualizado jamás (2017, 281ss). En efecto, en Ser y Tiempo Heidegger sostenía: "el que la realidad se funda ontológicamente en el ser del Dasein no puede significar que lo real solamente puede ser como lo que es en sí mismo si y mientras existe el Dasein" (Heidegger 2006a, 280). Esto no puede significar que lo real sólo es algo en sí mismo si y mientras existe Dasein. Como indica Gabriel sobre el análisis de Heidegger, allí "la posibilidad de conocer las cosas o de acceder a ellas depende de la existencia del Dasein, es decir, sin Dasein no habría ningún ser, en tanto esta expresión significa que los objetos en general están bajo condiciones de accesibilidad" $(2017,281)$. Es por tal motivo, porque el Dasein es posibilidad óntica de la comprensión del ser, que en $S u Z$ se afirmaba que

De todos modos, solo mientras el Dasein es, o sea, mientras es la posibilidad óntica de la comprensión del ser, 'hay' ser. Si el Dasein no existe, entonces tampoco 'es' la 'independencia' y tampoco es el 'en sí'. Entonces eso no es inteligible ni ininteligible. Y entonces tampoco el ente intramundano puede descubrirse, ni estar oculto. En tal caso no puede decirse ni que el ente es ni que no es. Ahora, mientras hay comprensión del ser y con ello comprensión de lo que está-ahí-delante, sin duda puede decirse que más adelante seguirá siendo lo que es. (Heidegger 2006a, 212)

$15 \mathrm{Al}$ respecto, Rubio sostiene que habría en Heidegger, a la luz de los pasajes referidos, la afirmación de una no-dependencia del estar-ahí natural en cuanto modo de ser respecto al Dasein. Tal cosa, indica acertadamente Rubio, implica "un cruce de accesibilidad e inaccesibilidad" del ente natural. Ahora bien, Rubio entiende que, por esta vía, Heidegger llega a un planteo ambivalente, cuando sostiene que "el ente natural es en tanto tal, independiente de su estar-descubierto. Según ello, la intramundaneidad no es condición ni del modo de ser del ente físico ni tampoco de que éste sea, al menos en un sentido. En otro sentido, en cambio, la no-dependencia del ente natural respecto al mundo se muestra sólo en tanto éste ingresa al mundo" (Rubio 2010, 333-334). Me parece que este veredicto es en general correcto, sobre todo respecto del acceso al ente natural. Sin embargo, el léxico de la no-dependencia de modo de ser podría inducir a confusión, si hace creer que Heidegger mantendría una 'dependencia manifestativa' (pues a la naturaleza descubierta le corresponde intramundaneidad), aunque afirme a la vez su independencia en cuanto modo de ser (entendiendo que al ser de la naturaleza no le pertenece la intramundaneidad). Evidentemente, tal cosa es un error, pues los modos de ser dependen de la manifestación, no así la onticidad; lo que remite al ya mencionado factum de que hay ente en general, tal como se verá de inmediato en el cuerpo del texto. 
En definitiva, si no se hubiese dado ningún Dasein, no habría tenido lugar el ser, pues ser y comprender están vinculados entre sí, y esto es condición de posibilidad de la verdad. Heidegger entiende, como remarca Gabriel $(2017,281)$, que el ser no habría tenido lugar sin Dasein, pero eso no implica que el ente no se habría dado de alguna manera, aunque no sepamos cuál sea.

¿No hay cierta vacilación en esos postulados, que tensionan internamente el argumento de Heidegger? Se le atribuye la independencia y dependencia al ser, pero no al ente, toda vez que el ente es independiente del ser en tanto que se da el ser. Sin embargo, el ente no habría sido independiente del ser si nadie hubiese comprendido el ser; tampoco el ente hubiese sido dependiente del ser si no se hubiese dado ningún ser. ${ }^{16}$ Por lo tanto, la doctrina del ingreso del ente en el mundo parece ambivalente, en la medida en que intenta aclarar cómo el ente natural, en su estar-ahí delante, es, o al menos puede ser, aunque no sea descubierto. Para explicitar esto, Heidegger enfatizará la noción de "ocultamiento":

El ente está totalmente oculto mientras no tenga lugar el ingreso en el mundo. Por consiguiente, en la palabra griega que significa verdad, alétheia, se encuentra una profunda intuición. El ente debe, antes que nada, ser sacado de su ocultamiento, que se le debe arrancar y se le quita gracias a que la temporeidad temporizante proporciona la ocasión para el ingreso en el mundo. (Heidegger 1978, 281)

La doctrina de la Welteingang des Seienden recibe ahora un sentido especulativo: se trata de un tránsito desde el total ocultamiento al desocultamiento del ente. ¿Qué significa ese 'ocultamiento'? Heidegger remite al fragmento 123 de Heráclito (phýsis krýptesthai phileî, que traduce como "el ente en sí y en su esencia ama ocultarse, permanecer en el ocultamiento"; Heidegger 1978, 281). Empero, ¿qué autoriza a hablar de "acentuación" de la estructura de ocultamiento? Podría objetarse una sobredimensión o trivialización del carácter auto-ocultante de cualquier fenómeno, toda vez que la

16 Según M. Gabriel, Heidegger sostiene un antirrealismo ontológico para defenderse de la posible objeción de antirrealismo óntico. En el contexto que analizamos sobre la dependencia e independencia, la estrategia de Heidegger para sortear las dificultades es, a ojos de Gabriel, atribuir al realista ontológico una "falacia de concreción equivocada" (proyectar condiciones de nuestra comprensión del ser a aquello de lo que suponemos que es el objeto de nuestro comprender), y para ello desarrollaría una respuesta excesiva, que consistiría en una posición de realismo anti-ontológico (Cf. Gabriel 2017, 282-283). Ahora bien, hay que destacar que, a propósito de Heidegger y el realismo ontológico, Gabriel remite al texto Das Argument gegen der Brauch (für das Ansichsein des Seienden) (Heidegger 2013-2014). Este asunto es especialmente relevante, pues a partir de él Gabriel afirma que la correlación de ser y Dasein en Heidegger corresponde a su vinculación con un realismo epistemológico o hermenéutico (2017, 285-286). Evidentemente, la dilucidación de este argumento, así como la revisión del mencionado texto de Heidegger, sobrepasa los límites de este trabajo, por lo que aquí me limito a dejarlo simplemente indicado. 
fenomenología heideggeriana parte precisamente del 'no estar dado' del fenómeno en su mostración, i.e., de su 'estado de oculto' (Cf. Heidegger 2006a, 35ss). Como dice Figal, "todo cuanto es, está dado en el Dasein, sólo a partir de éste se hace pensable un 'desocultamiento' de eso que es” $(2008,213)$. Ahora bien, podemos notar que la doctrina de la Welteingang establece la tesis según la cual el ente natural es, incluso sin aparecer (todavía) dentro del mundo, es decir, que es con independencia de su aparecer en el mundo. Esta tesis tiene la relevancia ontológica-fenomenológica de mantener en este contexto la tesis de que todo lo que es, se muestra en el Dasein y que el ser del existente humano es lo único en referencia a lo cual todo lo demás puede comprenderse como ente. Sin embargo, al mismo tiempo, el ente natural es en-sí, y su ingreso en el mundo es condición para que, como subsistente, se manifieste en su carencia de necesidad de entrar en el mundo. El planteo es ambivalente: no es necesario, pero sí posible, que el ente ingrese en el mundo.

La tesis que entiende el ingreso del ente en el mundo en el sentido de un tránsito desde el completo ocultamiento al desocultamiento, es la manera en que Heidegger pretende mostrar que el ser no habría tenido lugar sin $D a$ sein, pero que aquello no es contradictorio con el hecho de que el ente no se habría dado de alguna manera. El mencionado tránsito tiene un sentido especulativo, toda vez que pretende decirnos cómo es el ente en-sí 'antes' o independiente' de aparecer: algo completamente oculto y que en sí mismo permanece en el ocultamiento. Sin embargo, no es absolutamente inefable, ya que su ingreso en el mundo -y con ello su aparecer- no es necesario, sino esencialmente posible, y tal cosa es condición de posibilidad del descubrimiento del ente, que a su vez es esencialmente 'descubrible'. Se aprecia entonces que la inclusión de la noción de phýsis para acentuar la estructura ontológica de la verdad como alétheia permitirá a Heidegger profundizar en el momento de retracción aparentemente insuprimible del proceso manifestativo del ente natural. Con ello otorga un lugar destacado -que más tarde será central- a la relación entre manifestación y auto-ocultamiento de sentido, lo que implica comenzar a cuestionar la tesis de que el sentido de ser, como horizonte de comprensión que posibilita la manifestación de entes, sea un momento estructural del Dasein. La explicación del espacio de manifestación de sentido de ser implicaría tanto la apertura de sentido por parte del Dasein, como también la dimensión de ocultamiento en el sentido del en-sí inaccesible pero vinculado con la apertura misma, a la manera de una tensión entre ambas dimensiones. ${ }^{17}$

17 Cf. Rubio 2008, 300, que entiende que esa dimensión de ocultamiento es, por consiguiente, la de lo inaccesible, que sin embargo está vinculado con la apertura misma. 
Por lo tanto, la cuestión del ente natural y la doctrina de la Welteingang como tránsito del completo ocultamiento (phýsis) al desocultamiento (alétheia), entrega elementos para plantear el problema de la naturaleza en un sentido más amplio, en un sentido originario. Esto se vincula con la noción de trascendencia. Esta última, en tanto que sobrepasar el ente, en tanto que estar-en-el-mundo, significa que la existencia está entregada al ente (an das Seiende preisgegeben sein; Heidegger 1996, 326), y así puede comportarse respecto a él. Existir es un quedar expuesto respecto al ente; esto implica una determinación interna del estar-en-el-mundo como tal: el estar en medio de lo ente, i.e., que el Dasein esté entregado o consignado al ente significa que el ente impera en él:

El Dasein es cuerpo y carne [cuerpo vivo] y vida (Das Dasein ist Körper und Leib und Leben); tiene naturaleza y no como objeto de una consideración, sino que ella es naturaleza, pero no como la representación de un conglomerado de materia, cuerpo y alma. Es naturaleza en cuanto que trasciende los entes, en cuanto que Dasein, gobernado y templado por ella [por esa naturaleza que él es]. Es cada vez en el modo de un estar determinado y templado (Gestimmtseins) que el Dasein se encuentra (befindet sich) en medio del ente que impera en él. (Heidegger 1996, 328329)

Se trata de la naturaleza en sentido originario: un encuentro con lo natural acontece en las disposiciones afectivas del existente humano, provenientes de su condición de estar en medio de los entes. En efecto, este es un carácter básico de la trascendencia, pues a esta, como estar-en-el-mundo, le pertenece dicho estar en medio de lo ente que existe como algo que se encuentra en un estado de ánimo ${ }^{18}$, y por mor de ello la naturaleza se revela originariamente en el Dasein.

Por lo tanto, la cuestión del ente natural y la doctrina de la Welteingang des Seienden y su recurso a la noción de phýsis en tensión con alétheia entrega elementos para abordar el problema de la naturaleza en sentido originario. Se trata de un planteo de índole especulativa, que debe reconocer que, en el proceso manifestativo del ente natural, se da un cruce de accesibilidad

18 Este planteamiento está en consonancia con lo expuesto en De la esencia del fundamento sobre un posible acceso a la naturaleza en sentido originario. Allí Heidegger sostiene: "Pero si en la analítica del Dasein, así orientada, parece que falta la naturaleza (y no sólo la naturaleza como objeto de las ciencias de la naturaleza, sino también la naturaleza en sentido originario [...]), es porque existen motivos para ello. El motivo principal es que la naturaleza no es algo que se pueda encontrar ni en el ámbito del mundo que nos rodea ni mucho menos ni de modo primario como algo respecto a lo cual nosotros nos conducimos. La naturaleza se revela originariamente en el Dasein desde el momento en que éste existe en medio de lo ente como algo que se encuentra en un estado de ánimo. Pero desde el momento en que el hecho de encontrarse (el estar-arrojado) forma parte de la esencia del Dasein y es algo que se expresa en la unidad del concepto completo de cuidado, aquí lo único que podemos llegar a obtener es la base para el problema de la naturaleza" (Heidegger 1976, $156 n)$. 
e inaccesibilidad, lo que vuelve necesario plantear el aparecer en el mundo del ente natural recurriendo a la indicación de un momento de retracción sustractiva estructural en su manifestación, patente en el movimiento de sobrepasamiento descubridor de la trascendencia del Dasein, lo que da ocasión al ingreso del ente en el mundo.

\section{LA LECTURA DE LA TRADICIÓN METAFÍSICA Y LA CRISIS DE LA ONTOLOGÍA FUNDAMENTAL}

Una vez indicada la relevancia del recurso al concepto de phýsis en el ámbito ontológico-fenomenológico, cabe preguntar: ¿cuál es la proyección de este recurso en el contexto más amplio de la problemática metafísica? ¿Cómo se conecta con el ámbito filosófico-histórico, esto es, con la lectura de la tradición?

Aunque incipiente, el planteo de la dimensión de ocultamiento del ente en relación con la phýsis juega un papel importante en este sentido. El asunto reaparece al inicio del curso 1929/30, Los conceptos fundamentales de la metafísica. Heidegger explica la palabra 'metafísica', como acostumbraba en la época, a partir de Aristóteles, entendiendo filosofía como ciencia del ser. Se trata de un preguntar por la totalidad de lo ente y por la esencialidad del ser de lo ente. Empero, Heidegger antepone a esto una exposición sobre el significado de la palabra 'physiká' (que compone la expresión tà metà tà physiká), a partir de la phýsis heraclítea. Phýsis es lo que surge, lo que crece, el crecimiento. Heidegger propone traducirla como "imperar que se configura a sí mismo de lo ente en totalidad" (sich selbst bildenden Walten des Seienden im Ganzen; Heidegger 1983a, 38)

Heidegger direcciona la cuestión de la phýsis hacia una ligazón con lógos y alétheia, recurriendo nuevamente al fragmento 123 de Heráclito. Si la phýsis ama ocultarse, entonces se hace manifiesto por qué en el légein la phýsis fue desencubierta y arrancada del ocultamiento. El fragmento es traducido como "el imperar de las cosas tiene en sí mismo la tendencia a ocultarse". Heidegger visualiza una íntima conexión entre kríptein y lo que dice el lógos: la alétheia. El hombre es capaz de decir lo no oculto, y a una con ello actuar katà physin, introduciéndose y ajustándose en todo el imperar. Con esta interpretación Heidegger cree obtener el contexto intrínseco de la phýsis: el imperar de lo que impera; lógos es la palabra que obtiene este imperar del ocultamiento. Todo lo que sucede con esta palabra es asunto de la filosofía, que ahora se entiende como reflexión sobre el imperar de lo ente, para pronunciarla en el lógos (Heidegger 1983a, 42). Este planteamiento abre camino a Heidegger para interpretar la verdad como alétheia, como 
robo que tiene que arrancarse al ocultamiento, en confrontación o conflicto en que la phýsis, por su parte, intenta retraerse, ocultando lo más propio de ella. La alétheia muestra una conexión entre el imperar de lo ente, de su ocultamiento, y el hombre, que en el lógos arranca del ocultamiento a la phýsis, que trata de encubrirse. De este modo, el hombre trae lo ente a su verdad.

La operación interpretativa sobre el concepto de alétheia permite a Heidegger, mediante el recurso a Heráclito, esclarecer la noción de phýsis, que en general se entiende como 'lo imperante en su imperar', y establecer un doble significado del término: primero, lo propiamente imperante; luego, imperar de lo imperante. El primer significado se refiere a los physei óntaen contraposición con los tékhne ónta. La phýsis, como naturaleza, se entiende en sentido estricto, aunque más amplio que el concepto de la ciencia natural moderna. Phýsis es lo que ya siempre está-ahí delante por sí mismo, y que siempre está auto-constituyéndose y pereciendo, a diferencia de la hechura humana, que surge de la téchne de la producción (Heidegger 1983a, 46). ${ }^{19}$

El segundo significado de phýsis, según Heidegger, se refiere al imperar en cuanto tal como 'esencia y ley interna del asunto'. El imperar se entiende con igual originalidad que lo imperante, pues el imperar hace que todo lo imperante sea como es. En este momento phýsis no significa un dominio entre otros de lo ente, sino la 'más íntima esencia' de lo ente (Heidegger 1983a, 47). Empero, ninguno de estos significados de phýsis desplaza al otro, sino que se conservan en unidad, y por ello es convicción heideggeriana que la filosofía debe dirigir su preguntar hacia el imperar de lo ente en su totalidad. Heidegger pone esta lectura de la phýsis a la base de su interpretación de la próte philosophía aristotélica (cf. Heidegger 1983a, 48-87). Sin embargo, Heidegger resalta que en Aristóteles permanece el doble significado de

${ }^{19}$ A propósito de la interpretación heideggeriana del fragmento 123 de Heráclito, es importante consignar la oposición que Gadamer expresó respecto de tal exégesis. Gadamer sostiene que phýsis no habría tenido para Heráclito el peso filosófico que Heidegger le atribuye: “(...) Hay que suponer, más bien, que la verdadera formación del concepto no se produjo hasta que también se hubo formado su respectivo contraconcepto, y eso nos remite a la época de la sofística. Entonces se cuestionó, en el debate sobre el problema del lenguaje, si éste procede de la naturaleza o de la norma (nómos). El concepto «tékhne» tampoco aparece hasta época avanzada, y todo ello se adecua perfectamente con la sofística y con el uso platónico de phýsis en conexión con la psyche" (Gadamer 1999, 43). Para un comentario específico sobre phýsis en la lección 1929/30 vid. Beelman 1994, 32-36. Por otra parte, a propósito del vocablo phýsis y su ponderación en el pensamiento griego clásico, cf. Calvo 2000, 35; Cornford 1984, 93; Cornford 1987, 217; Guthrie 1984, 89; Guthrie 1986, 359 ss.; Jaeger 1993, 199-200; Llorente 2013, 119-145; Onians 1951, 247. Por último, para una consideración sobre Aristóteles y los temas indicados por Heidegger, véase Aubenque 1962 y 1985; Reale 1993 y 1994; Ross 1924 y 1936; Vigo 2007 y 2011; Wieland 1962. 
phýsis recién aludido. Por ejemplo, la ousía, el ente en cuanto ente, sería aún entendido como phýsis. La filosofía primera es entendida como indagación sobre la phýsis en doble sentido: pregunta por lo ente en totalidad, y también pregunta por la esencialidad o ser de lo ente (Heidegger 1983a, 48 ss.). Según Heidegger, Aristóteles "fusiona" estas dos direcciones del preguntar, encerradas en el significado unitario de phýsis. La filosofía primera es 'el auténtico filosofar': "es preguntar por la phýsis en este doble significado: preguntar por el ente en totalidad, y juntamente con ello, el preguntar por el ser" (Heidegger 1983a, 50; Cf. Heidegger 1997, 30). Dentro de esta misma operación interpretativa, lo theión es entendido como parte de la epistéme physiké. Esta no es recopilación de hechos en diversos ámbitos, sino que, como reflexión sobre la interna legalidad de todo este ámbito, pregunta qué es la vida, el alma, el surgir y perecer, el suceder, el movimiento, el lugar, el tiempo, el vacío que mueve todo lo movido, el primer motor. El auténtico preguntar en estas ciencias de la phýsis, dice Heidegger, es la pregunta suprema por el primer motor. A este elemento Aristóteles lo llama 'lo divino', sin un significado religioso, por cierto, sino en cuanto que es el carácter fundamental del movimiento, que a su vez determina lo ente en totalidad y su ser (Heidegger 1983a, 50-52).

Ahora bien, en el contexto descrito, hay que destacar que el desarrollo de una ontología general basada en esta recepción de la metafísica es interrumpido por Heidegger casi al cierre de esta misma lección. Heidegger renuncia a la ontología, al tematizar el 'enigma' de la diferencia ontológica; esta última necesitaría, arguye Heidegger, una nueva base para su posible tratamiento, pues quizás tal problemática ha sido obstaculizada de modo precipitado, al confiarla al dominio de la ontología y rotularla de ese modo. A ojos de Heidegger, el problema debe ser tratado con mayor radicalidad, corriendo por cierto el riesgo de tener que "rechazar toda ontología en su idea misma como una problemática metafísica insuficiente", e incluso concluir que "también la ontología y su idea deben caer, precisamente porque la radicalización de esa idea fue un estadio necesario del desarrollo de la problemática fundamental de la metafísica" (Heidegger 1983a, 522; subrayados de Heidegger). El veredicto sobre la 'radicalización' de la ontología fundamental comprendida como metafísica entiende que ese fue un movimiento insuficiente que forzaría a buscar bases para un enfoque aún más radical, aun cuando Heidegger no indica si lo mismo vale para el término 'metafísica'. Por lo demás, la renuncia a la ontología ocurre en la lección que pretende desplegar los conceptos fundamentales de la metafísica, de los que sólo fue analizado el concepto de mundo. 


\section{CONCLUSIONES}

Este trabajo se centró en la época 1927/30 de Heidegger, para analizar el recurso a la noción presocrática de phýsis. Dicha noción aparece con la elaboración de la doctrina de la Welteingang des Seienden, en el marco de una 'radicalización de la ontología', proyecto metafísico que luego hace crisis, lo que lleva a Heidegger a reinterpretar la pregunta por el sentido del ser como pregunta por la verdad del Ser. El curso del análisis mostró que la cuestión de la phýsis aporta elementos clave, tanto en el ámbito filosófico-histórico como el ámbito fenomenológico. La hipótesis sostenía que el empleo del concepto de phýsis en el marco de la doctrina de la Welteingang des Seienden implica un recurso de carácter especulativo que pretende aclarar el sentido en que el ente natural es, pero sin aparecer dentro del mundo, en términos de un tránsito desde el completo ocultamiento (phýsis) al desocultamiento del ente (alétheia). Esta comprensión de la phýsis tendrá luego consecuencias respecto a la evaluación de la tradición metafísica, mediante la progresiva acentuación de una dimensión de auto-ocultamiento en función de la estructura ontológica de la verdad (alétheia) comprendida como desocultamiento. En el registro histórico-filosófico, el concepto de phýsis tiene un doble significado que es proyectado como dualidad en la comprensión de la tradición metafísica: preguntar por la phýsis es preguntar por el ente en totalidad (el significado de phýsis como lo imperante: el ente que ya siempre está-ahí-delante por sí mismo) y, juntamente con ello, preguntar por el ser de lo ente o esencialidad (el imperar como esencia o ley interna).

Como se puede apreciar, el uso del concepto de phýsis, a propósito del ingreso del ente en el mundo, es un elemento de base para la posterior proyección del concepto de phýsis a la comprensión de la metafísica. En efecto, el mencionado tránsito desde ocultamiento a desocultamiento tiene un sentido especulativo en tanto recupera y expone la dimensión del factum brutum de que hay ente, a la vez que indica cómo es el ente en-sí 'independiente' de aparecer: algo completamente oculto y que en sí mismo permanece en el ocultamiento, pero que no es absolutamente inefable, ya que su ingreso en el mundo - y con ello su aparecer - no es necesario pero esencialmente posible, y tal cosa es condición de posibilidad del descubrimiento del ente, que a su vez es esencialmente 'descubrible'. Como se dijo, la inclusión de la noción de phýsis para acentuar la estructura ontológica de la verdad como alétheia permite a Heidegger profundizar en lo que sería un momento de retracción insuprimible en la manifestación del ente natural. Según esto, la cuestión del ente natural y la doctrina de la Welteingang des Seienden y su recurso a la noción de phýsis en tensión con alétheia, entrega elementos para abordar el problema de la naturaleza en sentido originario. Esto se evidencia 
en el movimiento de sobrepasamiento descubridor de la trascendencia del Dasein, que permite el ingreso del ente en el mundo. En otras palabras, si la verdad es un desocultar, es porque implica una tensión con una estructura no suprimible de ocultamiento. La introducción de dicha tensión implica acentuar los momentos estructurales de sustracción de sentido en procesos manifestativos que enfrenta el Dasein. Como han mostrado los especialistas (Jaran 2010; Rubio 2008, Tengelyi 2014; Vigo 2008; Volpi 2012), este interés es localizable en la época de transición estudiada, y por lo demás consecuente con el mencionado realce de la estructura ontológica de la verdad. Una clarificación exhaustiva del recurso a la instancia de auto-ocultamiento que posibilita el desocultamiento excede los límites de este trabajo. Empero, pueden indicarse algunos puntos: el interés en esta dimensión de ocultamiento estructural es concomitante con la reelaboración del fenómeno del lógos y su carácter veritativo en Aristóteles. Como ha señalado Volpi (2012, 157), de ello es especialmente llamativo el cambio de perspectiva para interpretar el carácter apofántico del lógos y su ser verdadero o falso. Volpi reconoce que anteriormente Heidegger remitió la posibilidad de ser verdadero o falso del discurso proposicional a la actitud descubridora del Dasein. Empero, en 1929/30, a la luz de la elaboración de las cuestiones directrices de la trascendencia y la configuración de mundo, Heidegger ubica la posibilidad de ser verdadero o falso en el ser-libre de descubrir del Dasein (Volpi 2012, 158). Deponer el acento en la actitud descubriente implica dejar de subrayar la función activa y fundante del Dasein. Por el contrario, al sostener luego que el fundamento reside en el ser-libre para descubrir del Dasein, lo que se enfatiza es "el horizonte ontológico a partir del cual tiene lugar el descubrimiento y por el cual está condicionado" (Volpi 2012, 158), destacando con ello la finitud del Dasein y el acontecer en el cual puede tener lugar el descubrimiento por parte del Dasein. Este no es sino el acontecer de la verdad en que el existente humano está siempre puesto ya como libre para descubrir. Estos asuntos, que prefiguran un cambio de perspectiva, reciben tratamiento directo en la conferencia de 1930, De la esencia de la verdad. Para Heidegger, todo proyecto de mundo, como proyecto de posibilidades del $D a$ sein, está caracterizado simultáneamente por un momento sustractivo de determinadas posibilidades ( $C f$. Heidegger 1976, 167). A esto hay que añadir, como hace Vigo $(2008,168)$, que el énfasis en el momento sustractivo dentro del movimiento de la trascendencia jugará un papel fundamental en la época de transición.

En 1930 el nuevo enfoque de la verdad implica que su esencia sea pensada como desocultamiento (Entborgenheit). La sustracción será entendida como no-verdad, esto es, como un estado de oculto (Verborgenheit) del ente 
en totalidad, lo que radicaliza el estar en la no-verdad de $S u Z$ (que se refería a la caída del Dasein en lo intramundano $C f$. 2006a, 221-223). La sustracción, como no-verdad, formará parte de la esencia de la verdad y, más aún, goza de un primado frente al momento manifestativo. Pensado desde la perspectiva de la verdad como desocultamiento (Entborgenheit), el encubrimiento (Verborgenheit) es el no-desocultamiento (Un-entborgenheit) y por ende la no-verdad más auténtica y propia de la esencia de la verdad (Heidegger 1976, 164). Como advierte Vigo, esto no habrá de entenderse como 'privación' de la venida a presencia de la verdad, sino de un encubrimiento que, al modo de una sustracción, ocurre en y con el acontecer de la verdad misma. Según esto, el primado del ocultamiento es señalado por Heidegger al sostener que "el encubrimiento de lo ente en su totalidad, la auténtica no-verdad, es más antiguo que todo carácter abierto de tal o cual ente" $(1976,164)$. El ocultamiento, la 'sustracción ocultante' (verbergende Entzug), detentará en 1930 un primado respecto a toda venida a presencia del ente y también respecto a todo desocultar el ente por parte del Dasein, pues el ocultamiento es también "más antiguo" que todo dejar-ser, el que, desencubriendo, ya mantiene oculto y se comporta ateniéndose al encubrimiento. Por lo tanto, refrendando lo expuesto en este trabajo, el pasaje recién citado debe entenderse en consonancia con la recuperación heideggeriana de las raíces ónticas de la ontología, i.e., la idea de que, solo por el Urfaktum de que hay ente, puede haber descubrimiento del ente y comprensión del ser. La metontología, entonces, puede entenderse como el intento de Heidegger por incluir la consideración de dicha dimensión óntica.

Ahora bien, sin perjuicio de lo anterior, el recurso a la alétheia y la dinámica de tensión de fuerzas de retraimiento y desencubrimiento se muestra aún en fase inicial, lo mismo que la orientación hacia el estudio de la phýsis. El desarrollo y delimitación de estas cuestiones en su unidad serán alcanzadas por Heidegger en los años 30-40. Sin embargo, es plausible sostener que este surgimiento de la cuestión de la phýsis es una de las problemáticas que entrega elementos para el ulterior enfoque autocrítico de Heidegger, en que cambiará también su enfoque de la tradición metafísica. 


\section{BIBLIOGRAFIA}

Aubenque, Pierre. 1977=1962. Le problème de l'être chez Aristote, Paris: PUF. Aubenque, Pierre et alii. 1985. Études aristotéliciennes. Métaphysique et théologie, Paris: Vrin.

Aristóteles 1990. Metafísica. Madrid: Gredos.

Beelman, Axel. 1994. Heideggers hermeneutischer Lebensbegriff. Würzburg: Königshausen \& Neumann.

Biemel, Walter. 1950. Le concept de monde chez Heidegger. Louvain: Nauvelaerts.

Calvo Martínez, Tomás. 2000. "La noción de Physis en los orígenes de la filosofía griega”, Daímon. Revista de Filosofía 21.

Cornford, Francis MacDonald. 1984. De la religión a la filosofía. Barcelona: Ariel.

. 1987. Principium sapientiae. Los orígenes del pensamiento filosófico griego. Madrid: Visor.

Courtine, Jean-François (ed.). 1996. Heidegger 1919-1929. De l'hermeneutique de la facticité a la métaphysique du 'Dasein'. Paris: Vrin.

Crowell, Steven G. 2001. Husserl, Heidegger, and the Space of Meaning: Paths Toward Transcendental Phenomenology. Evanston, IL: Northwestern University Press.

Dastur, Françoise. 1995. "Pour une zoologie privative". Alter. Revue de phénoménologie 3: 281-317.

Figal, Günter. 2008. "Heidegger y la fenomenología”. In Félix Duque (ed.), Heidegger, sendas que vienen. Madrid: UAM Ediciones.

Gabriel, Markus. 2017. Sentido y existencia. Una ontología realista (R. Gabás trad.). Barcelona: Herder.

Gadamer Hans-Georg. 1996. Mis años de aprendizaje. Barcelona: Herder. 1999. El inicio de la filosofía occidental. Barcelona: Paidós.

Greisch, Jean. 2010. La invención de la diferencia ontológica. Heidegger después de Ser y Tiempo. Buenos Aires: Las Cuarenta.

Guthrie, William Keith Chambers. 1984. Historia de la filosofía griega I. Los primeros presocráticos y los pitagóricos. Madrid: Gredos.

1986. Historia de la filosofía griega II. La tradición presocrática desde Parménides a Demócrito. Madrid: Gredos.

Haar, Michel. 2002. Heidegger et l'essence de l'homme. Paris: J. Millon.

Heidegger, Martin. 1950. Holzwege, GA Bd. 5. Frankfurt a. M.: V. Klostermann.

. 1975. Grundprobleme der Phänomenologie, GA Bd. 24. Frankfurt a.M.:

V. Klostermann.

1976. Wegmarken, GA Bd. 9. Frankfurt a.M.: V. Klostermann.

. 1978. Metaphysische Anfangsgründe der Logik im ausgang von Leibniz, GA Bd. 26. Frankfurt a.M.: V. Klostermann. 
1979. Heraklit, GA Bd. 55. Frankfurt a.M.: V. Klostermann.

. 1983a. Die Grundbegriffe der Metaphysik. Welt-Endlichkeit-Einsamkeit, GA Bd. 29/30. Frankfurt a.M.: V. Klostermann.

. 1983b. Einführung in die Metaphysik, GA Bd. 40. Frankfurt a.M.: V. Klostermann.

. 1996. Einleitung in die Philosophie, GA Bd. 27. Frankfurt a.M.: V. Klosterman.

1997. Der deutsche Idealismus (Fichte, Schelling, Hegel) und die philosophische Problemlage der Gegenwart, GA, Bd. 28. Frankfurt a.M.: V. Klostermann. . 2006a. Sein und Zeit. Tübingen: M. Niemeyer

.2006b. Geschichte der Philosophie von Thomas von Aquin bis Kant, GA Bd. 23. Frankfurt a.M.: Vittorio Klostermann.

- (2013-2014) Das Argument gegen den Brauch (für das Ansich-sein des Seienden-«der Natur»), Jahresgabe der Martin-Heidegger-Gesellschaft.

Jaeger, Werner. 1993. La teología de los primeros filósofos griegos. Madrid: FCE

Jaran, François. 2018 "El tránsito hacia un nuevo comienzo: la metafísica del Dasein (1927-1930”. In Rodríguez, R. (ed.), Guía Comares de Heidegger. Barcelona: Comares: 75-98 . 2010a. La métaphysique du Dasein. Heidegger et la possibilité de la metaphysique (1927-1930). Bucharest: Zeta Books. . 2010b. "Toward a Metaphysical Freedom: Heidegger's Project of a Metaphysics of Dasein". International Journal of Philosophical Studies 18-2: 205-227.

. 2008. "Una metafísica como remedio a la 'desolación total de la situación filosófica’ de los años 1920 (Martin Heidegger, Max Scheler)”. Pensamiento 64-241: 389-407.

. 2006. "La pensée metaphysique de Heidegger. La transcendance du Dasein comme source d'une metaphysica naturalis". Les études philosophiques 76-1: 47-61.

Llorente, Jaime. 2013. "Transitividad y fundamento. Reinterpretación del concepto de phýsis desde la perspectiva de una ontología negativa". Eikasía. Revista de Filosofía 49: 119-145.

Misch, Georg. 1967. Phänomenologie und Lebensphilosophie. Eine Auseinandersetzung der Diltheyschen Richtung mit Heidegger und Husserl. Darmstadt: WissenschaftlicheBuchgesellschaft.

Muñoz, Enrique. 2008. Der Mensch im Zentrum, aber nicht als Mensch. Zur Konzeption des Menschen in der ontologischen Perspektive Martin Heideggers. Würzburg: Ergon. 
Onians, Richard Broxton. 1951. The Origins of European Thought about the Body, the Mind, the Soul, the World, Time and Fate. New York: Cambridge University Press.

Ramos dos Reis, Róbson. 2010 "Natureza e normatividade na hermenêutica ontológica de Martin Heidegger". Natureza Humana 12-1: 1-46.

Reale, Giovanni. 1993. Aristotele, La Metafisica, vol. I-III, Milano. . 1994. Il concetto di "Filosofia Prima" et l'unità della Metafisica di Aristotele, Milano: Vita e pensiero.

Riedel, Manfred. 1989. "Naturhermeneutik und Ethik im Denken Heideggers". Heidegger Studies 5: 153-172.

1991. "Das Natürliche in der Natur." In H.-H. Gander (ed.) Von Heidegger her. Martin Heidegger Gesellschaft - Schriftenreihe. Band 1. Frankfurt am Main: V. Klostermann: 51-72.

Ross, William David. 1924. Aristotle's Metaphysics, vol. I-II, Oxford: Oxford University Press. 1936. Aristotle's Physics, Oxford: Oxford University Press.

Rubio, Roberto. 2004. "El concepto heideggeriano de 'formación de mundo' y su contexto". Escritos de Filosofía 44: 227-246. . 2008. “Continuidad de la cuestión de Dios en el pensar de Heidegger?La especificidad del planteo heideggeriano tras la crisis de Ser y Tiempo". Teología y Vida XLIX: 289-303.

. 2010 "Naturaleza y mundo en la transición del pensar de Heidegger tras Ser y Tiempo". In Actas del II Congreso Internacional de Fenomenología y Hermenéutica, Universidad Nacional Andrés Bello. Santiago: UNAB.

Tengelyi, László. 2014. Welt und Unendlichkeit. Zum Problem phänomenologischer Metaphysik. Freiburg; München: Karl Alber Verlag.

Thurnher, R. 1997. Wandlungen der Seinsfrage. Zur Krisis im Denken Heideggers nach "Sein und Zeit". Tübingen: Attempto Verlag.

Van Buren, John. 1994. The Young Heidegger. The Rumor of a Hidden King. Indiana: Indiana University Press.

Vigo, Alejandro. 2007. Aristóteles. Una introducción. Santiago: IES. . 2008. Arqueología y aleteiología y otros estudios heideggerianos. Buenos Aires: Biblos. . 2011. Estudios aristotélicos. Pamplona: Eunsa.

Volpi, Franco. 2012. Heidegger y Aristóteles. Buenos Aires: FCE.

Von Herrmann, Friedrich-Wilhelm. 1997. La 'segunda mitad' de Ser y Tiempo. Sobre Los problemas fundamentales de la Fenomenología de Heidegger. Madrid: Trotta.

Wieland, Wolfgang. 1962. Die aristotelische Physik. Untersuchungen über die Grundlegung der Naturwissenchaft un die sprachlichen Bedingungen der Prinzipienforschung bei Aristoteles. Göttingen: Vandenhoeck \& Ruprecht. 
Xolocotzi, Ángel. 2004 Fenomenología de la vida fáctica. Heidegger y su camino a Ser y Tiempo. México: Plaza y Valdés.

2005. "Fundamento, esencia y Ereignis. En torno a la unidad del camino del pensar de Martin Heidegger". Endoxa: Series Filosóficas 20: 733-744.

2009. Facetas heideggerianas. Puebla: Los Libros de Homero. 